\title{
Mechanism for Codeposition of Multiwalled Carbon Nanotubes with Copper from Acid Copper Sulfate Bath
}

\author{
Susumu Arai, ${ }^{*}$ and Akihiro Kato \\ Department of Chemistry and Material Engineering, Faculty of Engineering, Shinshu University, \\ Nagano 380-8553, Japan
}

\begin{abstract}
The mechanism involved in the codeposition of carbon nanotubes (CNTs) with copper from an acid copper sulfate bath was investigated. Multiwalled carbon nanotubes (MWCNTs) were employed and dispersed using polyacrylic acid. To determine the influence of the fibrous shape of the MWCNTs, codeposition was also carried out using copper and granular carbon black (CB). The effect of the polyacrylic acid on the dispersibility of MWCNTs and CB in the plating baths and the electrodeposition behavior of copper was investigated. In addition, the relationship between the initial MWCNT or CB concentration in the plating bath and that in the composite films was evaluated and the results are discussed based on the two-step adsorption model of Guglielmi. It was found that although for low MWCNT concentrations in the plating bath, this model could adequately explain the codeposition behavior, at higher concentrations, the MWCNT content in the deposit was larger than expected. It is suggested that the increased MWCNT content is related to the fibrous shape of the MWCNTs.

(C) 2013 The Electrochemical Society. [DOI: 10.1149/2.081309jes] All rights reserved.
\end{abstract}

Manuscript submitted May 2, 2013; revised manuscript received June 21, 2013. Published July 10, 2013.

Carbon nanotubes $(\mathrm{CNTs})^{1,2}$ have excellent mechanical characteristics, such as high tensile strength and elastic modulus, and exhibit high thermal and electrical conductivities. Recently, the fabrication of various metal/CNT composites, which are expected to be promising functional materials, has been attempted using plating techniques, and in particular, composite plating. ${ }^{3-11}$

The composite plating technique that was first reported by Sauter ${ }^{12}$ can produce metal films with a variety of functions, and has thus been widely researched for the fabrication of functional materials. However, practical applications of this technology have been limited to a few cases. Therefore, to increase the range of applications of CNT and other composite plating techniques, elucidation of the mechanism involved in the codeposition of particles with a metal is very important. There have been several reports on the kinetics and mechanism involved during composite plating using electrodeposition. Snaith and Groves first proposed the occurrence of mechanical bonding between a metal matrix and ceramic particles. ${ }^{13}$ Guglielmi developed a rate equation based on a two-step adsorption model. ${ }^{14}$ Celis and Roos proposed that the particle codeposition rate is determined by the reduction rate of metal ions that are adsorbed on the particles. ${ }^{15}$ Forester reported a codeposition mechanism based on the zeta potential. ${ }^{16}$ Hayashi et al. proposed that the amount of metal ions adsorbed on particles has an important influence on the codeposition behavior. ${ }^{17}$ Roos and coworkers also developed a mathematical model for codeposition. ${ }^{18,19}$ In all of these studies on the codeposition mechanism, hydrophilic granular particles such as alumina were used without dispersing agents. In contrast, multiwalled carbon nanotubes (MWCNTs) are hydrophobic and have fibrous shapes, and may therefore be expected to behave differently during the codeposition process. To clarify the mechanism involved in the codeposition of MWCNTs with a metal, the effect of the dispersant and the MWCNT shape should be evaluated.

In this study, the codeposition behavior of MWCNTs and copper from an acid sulfate bath containing a dispersant was investigated and the codeposition mechanism is discussed in terms of Guglielmi's theory.

\section{Experimental}

Commercially available vapor-grown MWCNTs (Showa Denko Co. Ltd.), formed via catalyst-assisted chemical vapor deposition (CVD) ${ }^{20}$ and heat treated at $2800^{\circ} \mathrm{C}$ in an argon gas atmosphere for $30 \mathrm{~min}$, were used. The MWCNTs were typically $100-150 \mathrm{~nm}$ in diameter and $10 \mu \mathrm{m}$ long. Granular carbon black (CB) particles were also used for comparison. Spherical or granular graphite particles with the same primary particle volume as the MWCNTs (ca. $400 \mathrm{~nm}$ in diameter) were not available. Therefore, commercially available CB (Asahi\#15, Asahi Carbon Co. Ltd., $122 \mathrm{~nm}$ diameter) with the closest primary particle volume to that of the MWCNTs was used. Scanning electron microscopy (SEM) images of the MWCNTs and CB used in the present study are shown in Fig. 1.

A copper sulfate solution $\left(0.85 \mathrm{~mol} \mathrm{dm}^{-3} \quad \mathrm{CuSO}_{4} \cdot 5 \mathrm{H}_{2} \mathrm{O}\right.$ $+0.55 \mathrm{~mol} \mathrm{H}_{2} \mathrm{SO}_{4}$ ) was used as the base copper plating bath. Since MWCNTs are hydrophobic and did not disperse uniformly in the base copper plating bath, polyacrylic acid (mean molecular weight 5000; PA5000) was employed as a dispersant. ${ }^{7-11}$ The dispersibility of the MWCNTs and CB in the plating baths was evaluated using a laser diffraction particle size analyzer (Shimadzu Seisakusho, SALD-7000). Samples of composite plating bath solutions containing $2 \mathrm{~g} \mathrm{dm}^{-3}$ of MWCNTs or CB with various concentrations of PA5000 were diluted 150 times with pure water to prepare suitable particle concentrations for the dispersibility measurements. The zeta potentials of the same diluted MWCNT and CB dispersions in plating bath solutions were also measured using an electrophoresis type zeta potential measurement system (Nihon Rufuto, Model 502). Cathode polarization measurements were conducted using an electrochemical measurement system (Hokuto Denko, HZ-5000) to clarify the effects of the PA5000 dispersant on the electrodeposition of copper. A pure copper plate, a copper plate containing a small amount of phosphorus, and a saturated calomel electrode (SCE) were used as the working, counter, and reference electrodes, respectively. Measurements were

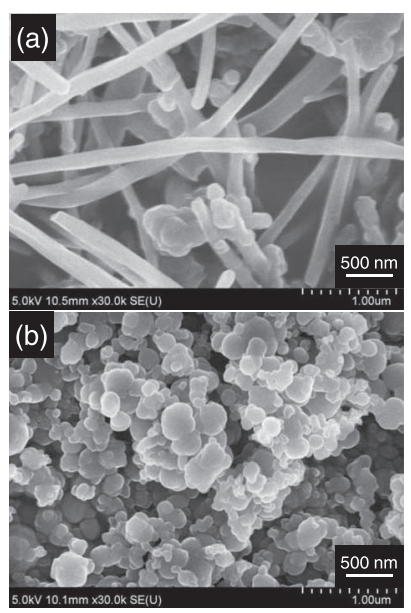


performed without agitation at $25^{\circ} \mathrm{C}$. The $\mathrm{Cu} / \mathrm{MWCNT}$ composite plating baths were prepared by the addition of PA5000 dispersant and MWCNTs to the base copper plating bath. A commercially available electrolytic cell (Microcell Model I, Yamamoto-Ms Co., Ltd.) with internal dimensions of $65 \times 65 \times 95 \mathrm{~mm}^{3}$ was employed for electrodeposition. The volume of the plating bath was $250 \mathrm{~cm}^{3}$. A pure copper plate with an exposed surface area of $10 \mathrm{~cm}^{2}\left(3 \times 3.33 \mathrm{~cm}^{2}\right)$ was used as the substrate, and a copper plate containing a small amount of phosphorus was used as the anode. Electrodeposition was performed under galvanostatic conditions $\left(0.5\right.$ and $\left.1 \mathrm{~A} \mathrm{dm}^{-2}\right)$ with aeration at $25^{\circ} \mathrm{C}$. The quantity of electricity used was $600 \mathrm{C}$ $\left(60 \mathrm{C} \mathrm{cm}^{-2}\right)$.

The surface and cross-sectional morphologies of the $\mathrm{Cu} / \mathrm{MWCNT}$ and $\mathrm{Cu} / \mathrm{CB}$ composite films were examined using field-emission scanning electron microscopy (FE-SEM; JEOL JSM-7000F). A specialized sample preparation system (Cross-section polisher, JEOL SM-09010) was used to prepare cross-sectional samples for FE-SEM observation. The MWCNT and CB contents in the composite films were determined by direct weighing, for which purpose thick composite films (over $2 \mathrm{~g}$ in weight) were electrodeposited. After weighing the total composite film, the copper matrix of the film was dissolved in nitric acid. The MWCNTs or CB in the nitric acid solution were then filtered, dried and weighed.

\section{Results and Discussion}

Figure 2 shows particle size distributions for the MWCNTs and $\mathrm{CB}$ in the (diluted) composite plating baths. The dispersibility of the MWCNTs and CB tended to increase with PA5000 concentration. Figure 2a shows typical particle size distributions for the $\mathrm{Cu} / \mathrm{MWCNT}$ composite plating bath with PA5000 concentrations of $2 \times 10^{-6}$ and $2 \times 10^{-5} \mathrm{M}$. For a PA5000 concentration of $2 \times 10^{-6} \mathrm{M}$, two large peaks are evident at around $100 \mathrm{~nm}$ and $30 \mu \mathrm{m}$. The peak at $30 \mu \mathrm{m}$ indicates the aggregation of MWCNTs to form secondary particles. For a PA5000 of $2 \times 10^{-5} \mathrm{M}$, two large peaks are observed at around $100 \mathrm{~nm}$ and $10 \mu \mathrm{m}$, which are considered to correspond to the diameter and length of individual MWCNTs, respectively. ${ }^{21}$ Thus, for
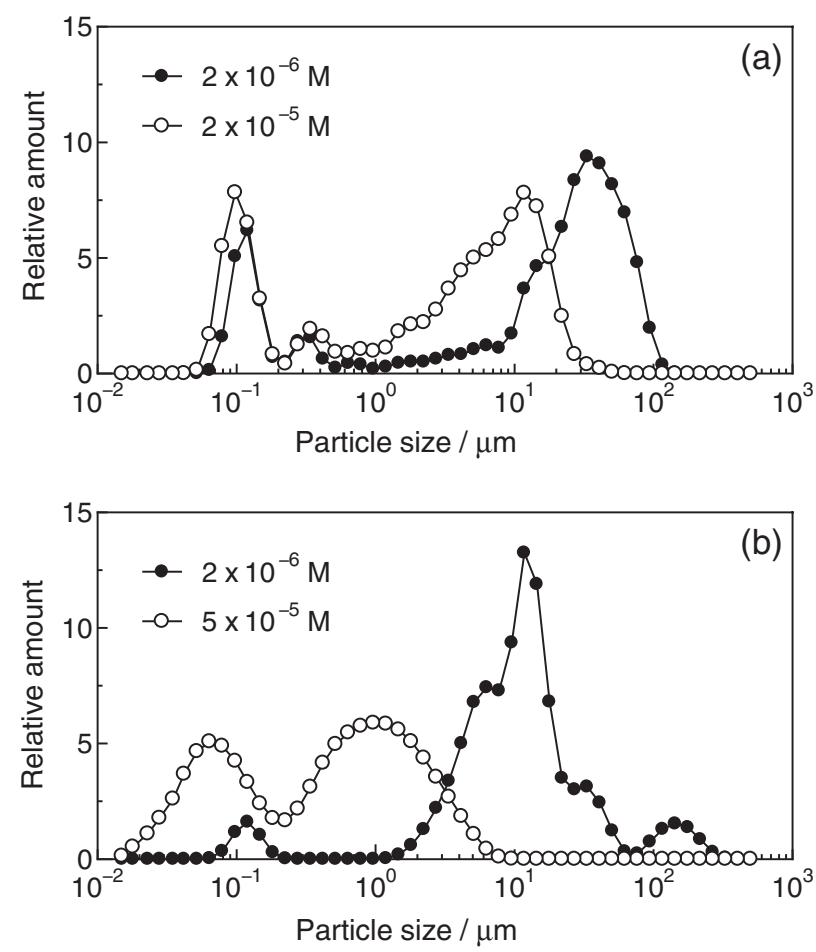

Figure 2. Particle size distribution for (a) MWCNTs and (b) CB in composite plating bath solutions with various PA5000 dispersant concentrations.
Table I.

Zeta Potential $(\mathrm{mV})$

\begin{tabular}{lcc}
\cline { 2 - 3 } Conc. of PA5000 $(\mathrm{M})$ & MWCNTs & CB \\
\hline $2 \times 10^{-6}$ & -4.4 & +8.6 \\
$2 \times 10^{-5}$ & -6.2 & +8.0 \\
$2 \times 10^{-4}$ & -5.0 & +7.2
\end{tabular}

this PA5000 concentration, the MWCNTs are thought to be homogeneously distributed as primary particles. For PA5000 concentrations higher than $2 \times 10^{-5} \mathrm{M}$, it was found that no further change in the particle size distribution occurred. Figure $2 b$ shows typical particle size distributions for the $\mathrm{Cu} / \mathrm{CB}$ composite plating bath with PA5000 concentrations of $2 \times 10^{-6}$ and $5 \times 10^{-5} \mathrm{M}$. For a PA5000 concentration of $2 \times 10^{-6} \mathrm{M}$, the dominant peak is at around $10 \mu \mathrm{m}$, which indicates aggregation of the majority of $\mathrm{CB}$ particles to form secondary particles. In contrast, for a PA5000 concentration of $5 \times 10^{-5} \mathrm{M}$, two large peaks are found at around $80 \mathrm{~nm}$ and $1 \mu \mathrm{m}$. Since the average diameter of the CB particles is about $100 \mathrm{~nm}$, these peaks are considered to correspond to primary and secondary particles, respectively. No further improvement in the dispersibility of the $\mathrm{CB}$ particles occurred for PA5000 concentrations higher than $5 \times 10^{-5} \mathrm{M}$. Thus, for both type of particles, PA5000 was found to be an effective dispersant, and particularly for MWCNTs. From the results shown in Fig. 2, the optimum PA5000 concentration to disperse $2 \mathrm{~g} \mathrm{dm}^{-3}$ of MWCNTs and $\mathrm{CB}$ was $2 \times 10^{-5}$ and $5 \times 10^{-5} \mathrm{M}$, respectively.

Table I shows the measured zeta potentials for MWCNTs and CB in (diluted) plating bath solutions with various PA5000 concentrations. The zeta potentials for the MWCNTs were all negative, whereas those for the CB particles were all positive. This may be due to the difference in the electronic states at the surfaces of MWCNTs and CB. However, the absolute zeta potentials for both the MWCNTs and $\mathrm{CB}$ are very low (several millivolts). Stable dispersion of nanoparticles in solutions using polymeric dispersants generally occurs due to electrostatic and/or steric repulsion. Since the zeta potentials for both the MWCNTs and CB are very low, stable dispersion is likely to be mainly the result of steric repulsion of adsorbed PA5000 on the carbon particles. The low zeta potentials also suggest that the effect of electrophoresis on the codeposition mechanism is not dominant.

Although the zeta potential results indicate that adsorbed PA5000 acts as a dispersant, free PA5000 is also present in the composite plating bath solution, and this is likely to have an effect on the electrodeposition of copper. To clarify this effect, cathode polarization measurements were carried out. Figure 3 shows cathode polarization curves for copper plating baths (without carbon particles) containing various concentrations of PA5000. The solid line shows the electrodeposition behavior of copper from the base copper plating bath. It can be seen that the polarization curves shift toward negative values with increasing PA5000 concentration. Thus, PA5000 acts not only as a dispersant for the MWCNTs and CB, but also inhibits copper electrodeposition. The electrodeposition of copper from an acid sulfate bath generally advances according to a two-step reduction reaction: ${ }^{22-24}$

$$
\begin{gathered}
\mathrm{Cu}^{2+}+\mathrm{e}^{-} \rightarrow \mathrm{Cu}^{+} \\
\mathrm{Cu}^{+}+\mathrm{e}^{-} \rightarrow \mathrm{Cu}
\end{gathered}
$$

It has been proposed that the rate-determining step for the reduction process is reaction $1 .^{22-25}$ To clarify the effect of PA5000 on the electrodeposition mechanism for copper, a Tafel analysis (Tafel plot) was performed using the following equation:

$$
\operatorname{In}(-j)=-n \alpha \frac{F}{R T} \eta+\operatorname{In}\left(j_{0}\right)
$$

where $j, n, \alpha, F, R, T, \eta$, and $j_{0}$ are the current density, the number of electrons that participate in the rate-determining reaction (in this case $n=1$ ), the transfer coefficient, the Faraday constant, the absolute 


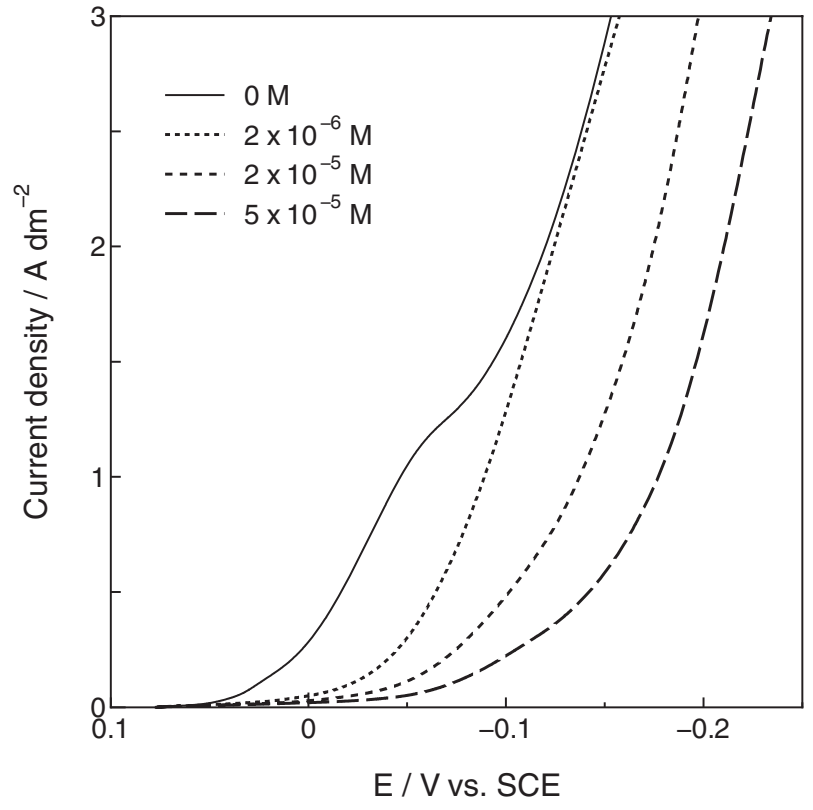

Figure 3. Cathode polarization curves for copper plating baths with various concentrations of PA5000 dispersant.

temperature, the cathode overpotential, and the exchange current density, respectively. The results of the analysis are shown in Table II. The transfer coefficient for the base copper plating is 0.45 , which is similar to that reported previously $(\alpha=0.50) .^{22}$ Even when the PA5000 concentration is varied, the transfer coefficients are seen to be around 0.50, which indicates that the electrodeposition mechanism does not change significantly, even in the presence of PA5000. In contrast, the exchange current density is seen to decrease with increasing PA5000 concentration. The following equation was proposed by Stankovic and Vukovic ${ }^{26}$ for the exchange current density in a copper sulfate plating bath with adsorbable molecules, based on a kinetic equation: ${ }^{27}$

$$
\begin{aligned}
j_{0} & =2 \mathrm{FC}_{\mathrm{Cu}^{2}+k_{c}} \exp \left(\frac{-\alpha_{c} \mathrm{FE}_{\mathrm{e}}}{\mathrm{RT}}\right)(1-\theta) \\
& =2 \mathrm{FC}_{\mathrm{Cu}}+k_{a} \exp \left(\frac{-\alpha_{a} \mathrm{FE}_{\mathrm{e}}}{\mathrm{RT}}\right)(1-\theta),
\end{aligned}
$$

\begin{tabular}{lcc}
\hline Table II. & & \\
$\begin{array}{l}\text { Conc. of } \\
\text { PA5000 (M) }\end{array}$ & $\begin{array}{c}\text { Transfer } \\
\text { coefficient }\end{array}$ & $\begin{array}{c}\text { Exchange current } \\
\text { density }\left(\mathrm{A} \mathrm{dm}^{-2}\right)\end{array}$ \\
\hline 0 & 0.45 & $9.2 \times 10^{-2}$ \\
$2 \times 10^{-6}$ & 0.41 & $6.1 \times 10^{-2}$ \\
$2 \times 10^{-5}$ & 0.51 & $1.2 \times 10^{-2}$ \\
$5 \times 10^{-5}$ & 0.55 & $4.3 \times 10^{-3}$
\end{tabular}

where $j_{0}, \mathrm{~F}, \mathrm{C}_{\mathrm{Cu} 2+}, \mathrm{C}_{\mathrm{Cu}+}, k_{\mathrm{c}}, k_{\mathrm{a}}, \alpha_{\mathrm{c}}, \alpha_{\mathrm{a}}, \mathrm{E}_{\mathrm{e}}, \mathrm{R}, \mathrm{T}$, and $\theta$ are the exchange current density, the Faraday constant, the equilibrium concentration of $\mathrm{Cu}^{2+}$, the equilibrium concentration of $\mathrm{Cu}^{+}$, the cathodic and anodic rate constants, the transfer coefficients for the reductive and oxidative reactions, the equilibrium potential of the copper electrode, the gas constant, the absolute temperature, and the fractional coverage of adsorbed molecules, respectively. PA5000 may become adsorbed on the cathode surface (electrodeposited copper surface), and its fractional coverage may increase with PA5000 concentration. This would result in a decrease of the exchange current density, which would lead to a suppression of copper electrodeposition, as indicated in Fig. 3.

Figure 4 shows surface SEM images of copper films electrodeposited at $0.5 \mathrm{~A} \mathrm{dm}^{-2}$ with various PA5000 concentrations in the plating baths. For reference, Fig. $4 \mathrm{a}$ and $4 \mathrm{e}$ show lowand high-magnification images of a pure copper film, respectively. It can be seen that the surface roughness increases gradually with PA5000 concentration (Fig. 4a-4c, Fig. 4e-4g). For a PA5000 concentration of $2 \times 10^{-4} \mathrm{M}$, the surface roughness is greater than $10 \mu \mathrm{m}$ (Fig. 4d, 4h). Thus, the presence of PA5000 affects the surface morphology of the electrodeposited copper films. Similar results were obtained at a current density of $1 \mathrm{~A} \mathrm{dm}^{-2}$.

Figure 5 shows surface SEM images of $\mathrm{Cu} / \mathrm{MWCNT}$ composite films electrodeposited at $0.5 \mathrm{~A} \mathrm{dm}^{-2}$ with various MWCNT concentrations in the plating bath. For the MWCNT concentration of $2 \mathrm{~g}$ $\mathrm{dm}^{-3}$, the suitable PA5000 concentration was $2 \times 10^{-5} \mathrm{M}$ (Fig. 2a). Therefore, the PA5000 concentration was changed in proportion to the MWCNT concentration in order to obtain a homogeneous dispersion of MWCNTs; the rate was $1 \times 10^{-5} \mathrm{M}$ PA5000 per $1 \mathrm{~g} \mathrm{dm}^{-3}$ of MWCNTs. From the low-magnification images, there is no significant change in the surface morphology with MWCNT concentration (Fig. 5a-5d). In addition, the high-magnification images show that MWCNTs are incorporated into all of the films (Fig. 5e-5h). However, by comparing Fig. 5e-5h and Fig. 4g, it can clearly be seen that the copper grain size is smaller in all of the composite films than in a
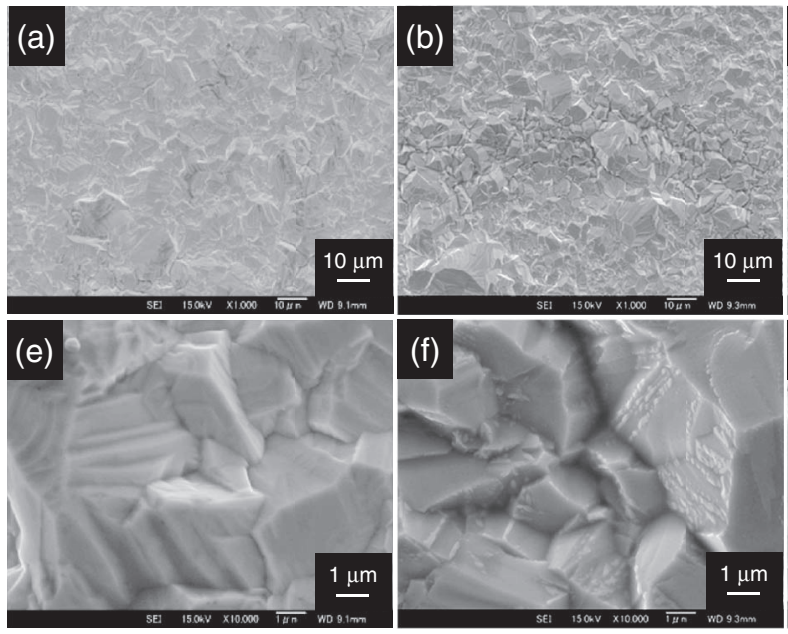
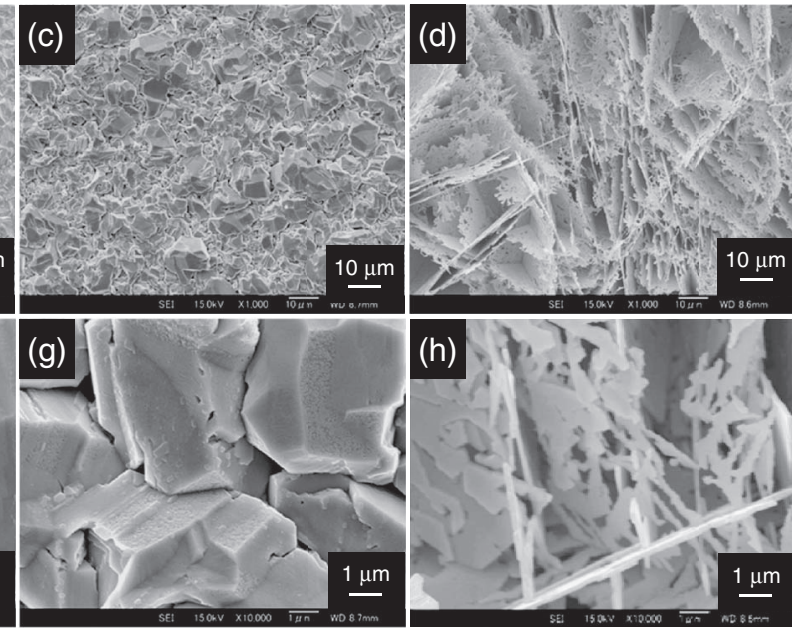

Figure 4. Surface SEM images of copper films electrodeposited from copper plating baths with PA5000 concentrations of (a) 0 , (b) $2 \times 10^{-6}$, (c) $2 \times 10^{-5}$, and (d) $2 \times 10^{-4}$ M. (e-h) High-magnification images of (a-d), respectively. 

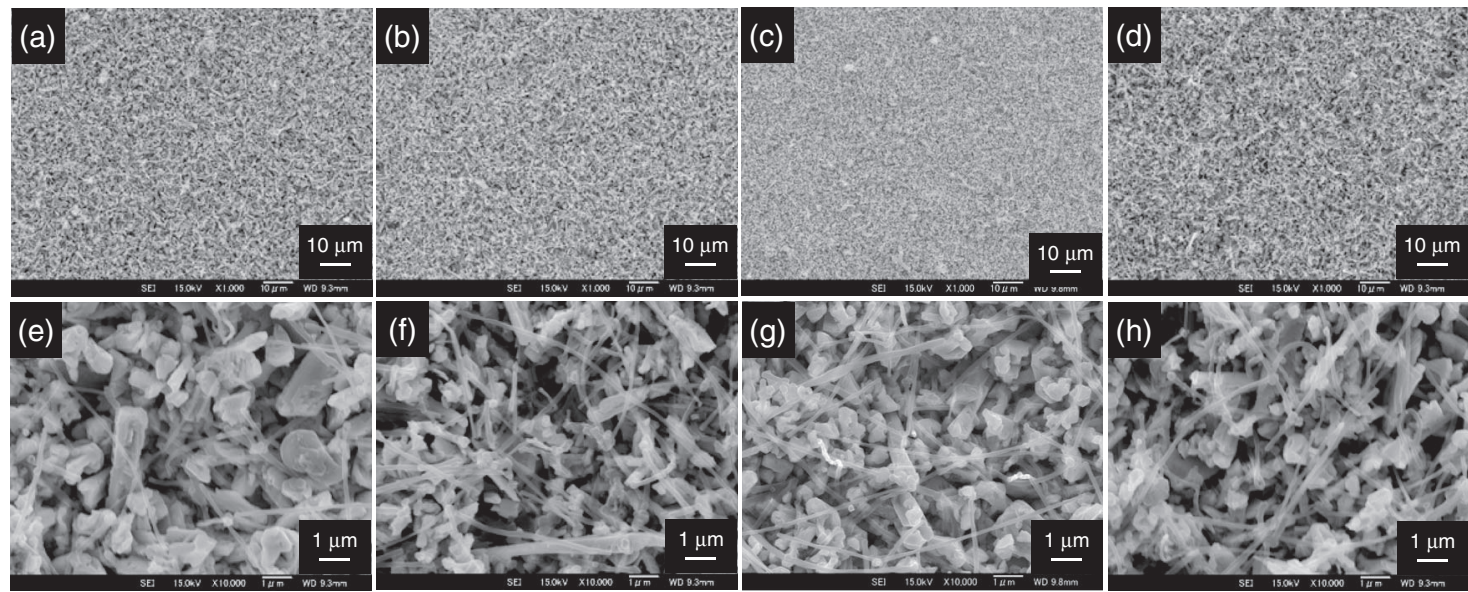

Figure 5. Surface SEM images of Cu/MWCNT composite films electrodeposited from composite plating baths with MWCNT concentrations of (a) 1 , (b) 2, (c) 3 , and (d) $5 \mathrm{~g} \mathrm{dm}^{-3}$. (e-h) High-magnification images of (a-d), respectively.

pure copper film deposited using a similar PA5000 concentration. This may be due to the suppression of copper grain growth by the presence of MWCNTs. Similar surface morphology results were obtained for $\mathrm{Cu} / \mathrm{MWCNT}$ composite films deposited at a current density of $1 \mathrm{~A}$ $\mathrm{dm}^{-2}$

Figure 6 shows surface SEM images of $\mathrm{Cu} / \mathrm{CB}$ composite films electrodeposited at $0.5 \mathrm{~A} \mathrm{dm}^{-2}$ with various $\mathrm{CB}$ concentrations in the plating baths. For the $\mathrm{CB}$ concentration of $2 \mathrm{~g} \mathrm{dm}^{-3}$, the suitable PA5000 concentration was $5 \times 10^{-5} \mathrm{M}$ (Fig. 2b). Therefore, the PA5000 concentration was changed in proportion to the CB concentration in order to obtain a homogeneous dispersion of $\mathrm{CB}$; the rate was $2.5 \times 10^{-5} \mathrm{M}$ PA5000 per $1 \mathrm{~g} \mathrm{dm}^{-3}$ of CB. The low-magnification images (Fig. 6a-6d) show a significant change in the surface morphology with $\mathrm{CB}$ concentration. The surfaces are seen to be relatively smooth for $\mathrm{CB}$ concentrations less than $2 \mathrm{~g} \mathrm{dm}^{-3}$, whereas above this, the surface roughness significantly increases to more than $10 \mu \mathrm{m}$. The high-magnification SEM images confirm that CB was incorporated into every film (Fig. 5e-5h). The copper grain size for low CB concentrations (Fig. 6e, 6f) is smaller than that for a pure copper film deposited with a similar PA5000 concentration (Fig. 4g). Again, this may be due to the suppression of copper grain growth by the presence of $\mathrm{CB}$. The significant change in morphology that occurs for $\mathrm{CB}$ concentrations of greater than $2 \mathrm{~g} \mathrm{dm}^{-3}$ (Fig. 6c, 6d, 6g, 6h) may be mainly due to the adsorption of PA5000 (Fig. 4d, 4h). Similar re- sults were obtained for $\mathrm{Cu} / \mathrm{CB}$ composite films deposited at a current density of $1 \mathrm{~A} \mathrm{dm}^{-2}$.

Figure $7 \mathrm{a}$ and $7 \mathrm{~b}$ show cross-sectional SEM images of the $\mathrm{Cu} / \mathrm{MWCNT}$ and $\mathrm{Cu} / \mathrm{CB}$ composite films shown in Fig. 5f and 6f, respectively. The MWCNTs are seen to be homogeneously distributed throughout the film. On the other hand, although the $\mathrm{CB}$ is present throughout the film in Fig. 7b, a large amount of aggregation is observed. These microstructures are consistent with the particle size distributions in the composite plating baths shown in Fig. 2. The $\mathrm{Cu} / \mathrm{MWCNT}$ composite films shown in Fig. $5 \mathrm{e}, 5 \mathrm{~g}$, and $5 \mathrm{~h}$ were found to have similar cross-sectional microstructures to that in Fig. 7a, whereas the $\mathrm{Cu} / \mathrm{CB}$ composite film shown in Fig. 6e had a similar microstructure to that in Fig. $7 \mathrm{~b}$. For the $\mathrm{Cu} / \mathrm{CB}$ composite films shown in Fig. $6 \mathrm{~g}$ and $6 \mathrm{~h}$, the $\mathrm{CB}$ distribution was similar to that in Fig. $7 \mathrm{~b}$, but with a porous copper matrix, as expected from the observed surface morphology.

Figure 8 shows the relationship between the carbon particle concentration in the composite plating bath and the carbon particle content in the deposits for a current density of $0.5 \mathrm{~A} \mathrm{dm}^{-2}$. The amount of codeposited MWCNTs and CB generally increases with the particle concentration in the plating bath. A nonlinear relationship is observed for MWCNTs in the concentration range of 0.5 to $3 \mathrm{~g} \mathrm{dm}^{-3}$, and for $\mathrm{CB}$ in the concentration range of 0.5 to $2 \mathrm{~g} \mathrm{dm}^{-3}$, which is typical for a codeposition mechanism based on an adsorption process. The
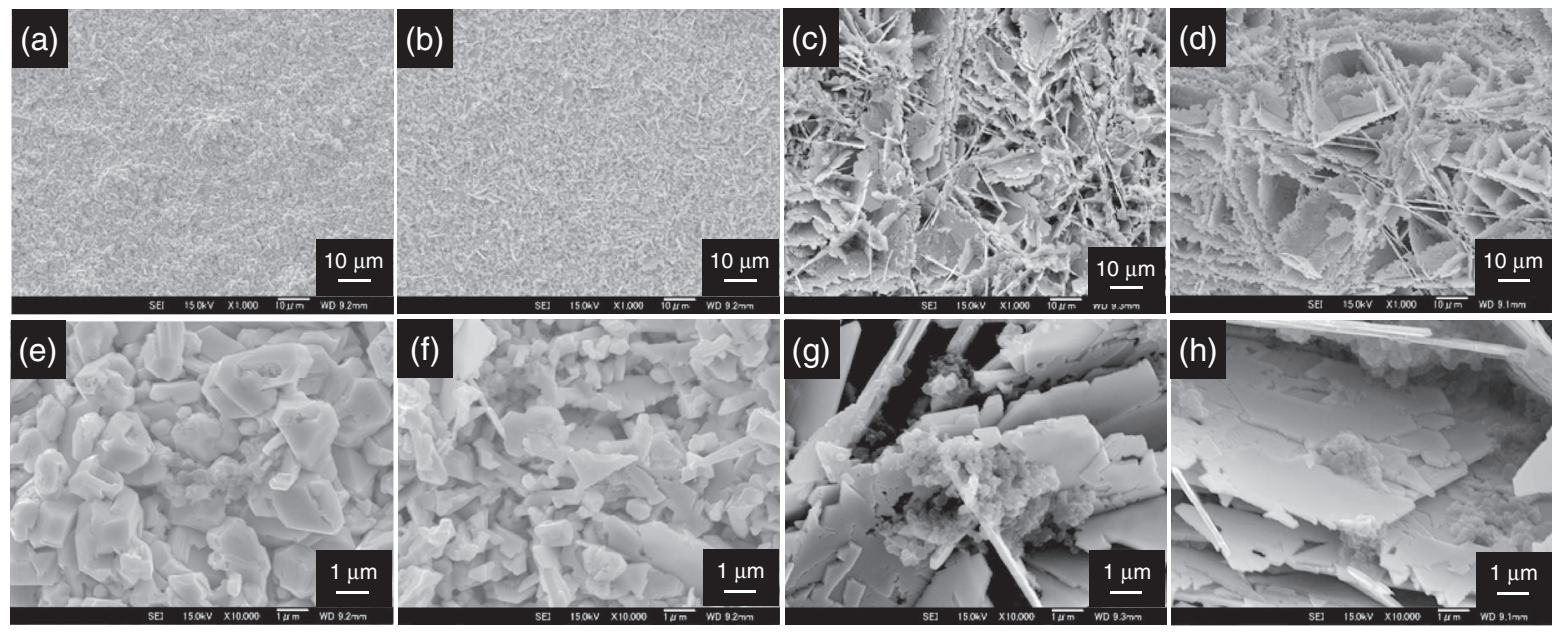

Figure 6. Surface SEM images of Cu/CB composite films electrodeposited from composite plating baths with CB concentrations of (a) 1 , (b) 2 , (c) 3 , and (d) $5 \mathrm{~g}$ $\mathrm{dm}^{-3}$. (e-h) High-magnification images of (a-d), respectively. 


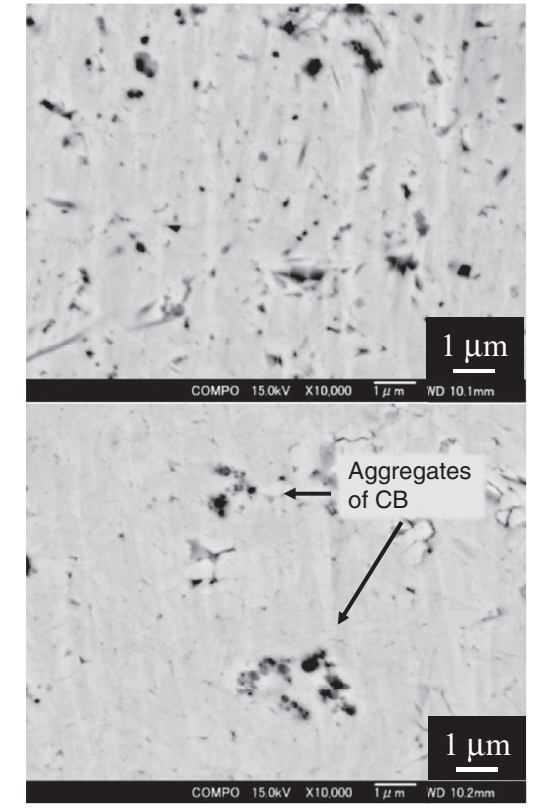

Figure 7. Cross-sectional SEM images of (a) Cu/MWCNT composite film and (b) $\mathrm{Cu} / \mathrm{CB}$ composite film, corresponding to Fig. $5 f$ and 6 , respectively.

MWCNT content in the films is seen to increase rapidly for MWCNT bath concentrations greater than $3 \mathrm{~g} \mathrm{dm}^{-3}$. Similarly, for $\mathrm{CB}$ concentrations greater than $2 \mathrm{~g} \mathrm{dm}^{-3}$, the $\mathrm{CB}$ content in the film increases significantly and exhibits large fluctuations. This large increase in $\mathrm{CB}$ content is consistent with the observed increase in surface roughness (Fig. 6c, 6d, 6g, 6h), which would lead to an increase in the specific surface area. Similar relationships to those shown in Fig. 8 were obtained at a current density of $1 \mathrm{~A} \mathrm{dm}^{-2}$

To clarify the details of the codeposition mechanism, the mechanism proposed by Guglielmi is considered, in which the rate equation is given as: ${ }^{14}$

$$
\frac{C}{\alpha}=\frac{W j_{\mathrm{o}}}{n F d V_{\mathrm{o}}} e^{(A-B)} \eta\left(\frac{1}{k}+C\right),
$$

where $C$ is the concentration (volume fraction) of particles in the plating bath, $\alpha$ is the volume fraction of particles in the composite film, $W$ is the atomic weight of the metal (in this study,

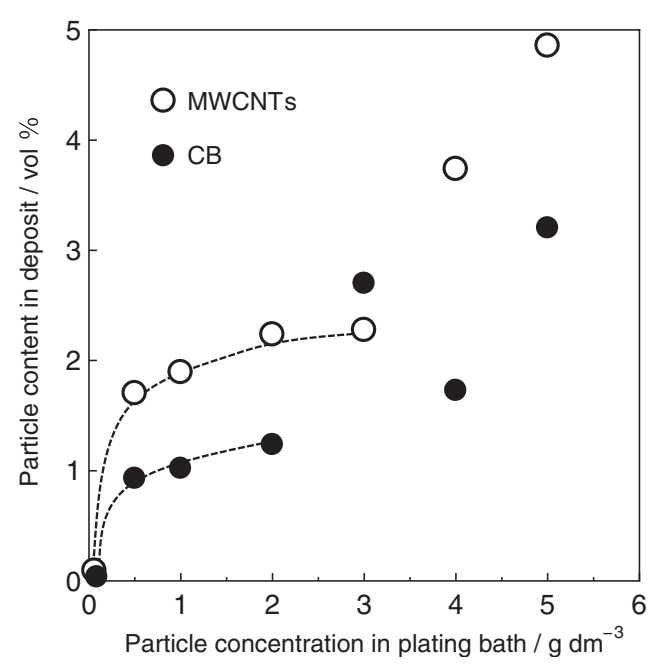

Figure 8. Relationship between carbon particle concentration in the plating bath and carbon particle content in the deposits.

$W=63.45$ ), $j_{0}$ is the exchange current density, $n$ is the valence (in this study, $n=2), F$ is the Faraday constant, $d$ is the density of the metal, $A, B, V_{0}$ and $k$ are constants, and $\eta$ is the cathode overpotential. From Eq. 5, if $C / \alpha$ is plotted against $C$ for different values of $\eta$, it represents a sheaf of straight lines having a slope equal to the factor outside the parenthesis.

Figure 9 a and $9 \mathrm{~b}$ shows $C / \alpha$ versus $C$ for $\mathrm{Cu} / \mathrm{MWCNT}$ and $\mathrm{Cu} / \mathrm{CB}$ composite films, respectively, at current densities of 0.5 and $1 \mathrm{~A} \mathrm{dm}^{-2}$. In Fig. 9a, although the data appears linear for lower particle concentrations $(C<0.15)$, it departs from linearity for higher $C$ values. In Fig. 9b, the data appears linear for $C<0.1$ before becoming nonlinear for higher $C$ values. Thus, it may be concluded that for both MWCNTs and $\mathrm{CB}$, codeposition with copper from an acid sulfate bath proceeds according to Guglielmi's two-step adsorption process only in the case of lower particle concentrations. Strictly speaking, in order to make the discussion more accurate, the concentration of free PA5000 in each plating bath should be estimated or measured. As shown in Table II, $j_{0}$ is a variable because it changes with the PA5000 concentration. In the present study, the PA5000 concentration was made to be proportional to the MWCNT and CB concentrations in order to achieve improved dispersion, and the concentration of PA5000 that is not adsorbed on the MWCNTs and CB (free PA5000) in each plating bath may differ.
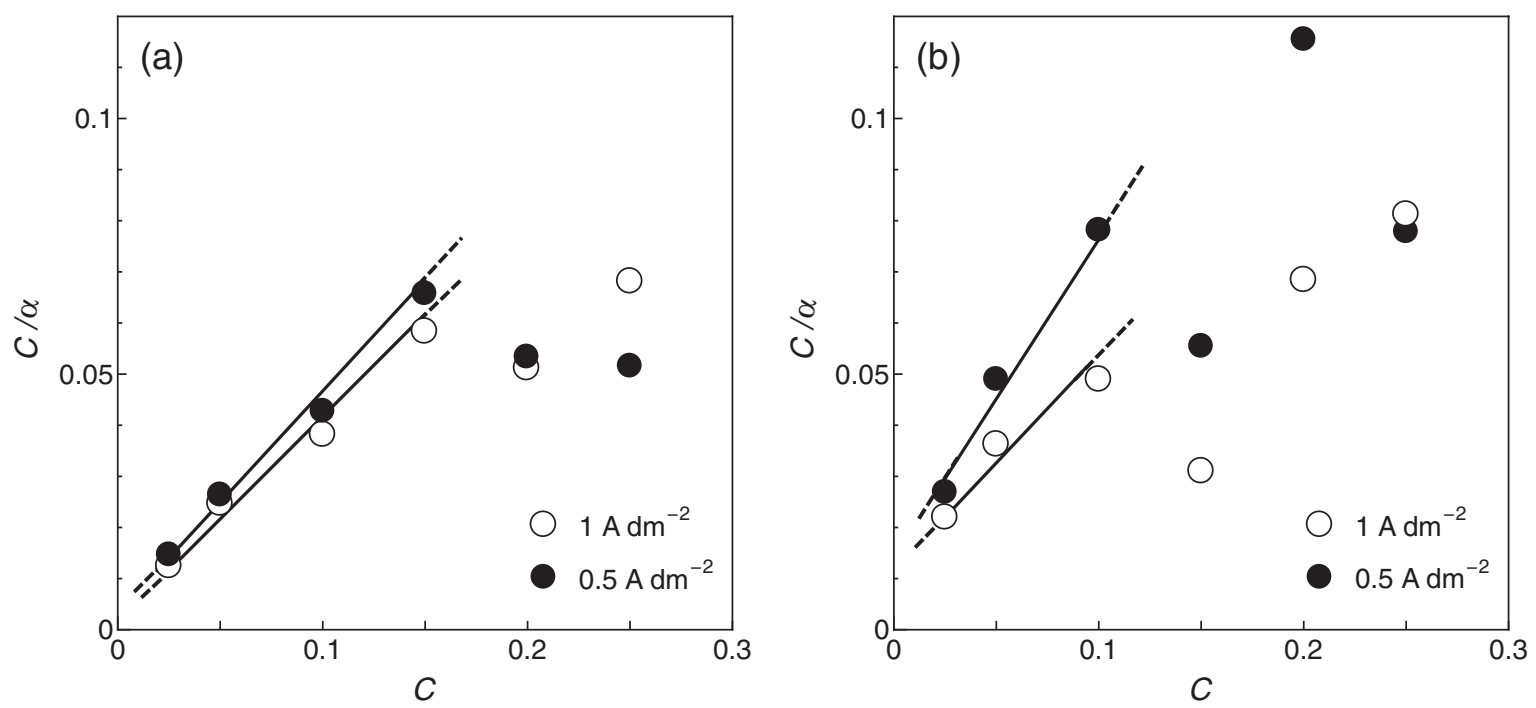

Figure 9. $C$ versus $C / \alpha$ plots for (a) $\mathrm{Cu} / \mathrm{MWCNT}$ composite plating and (b) $\mathrm{Cu} / \mathrm{CB}$ composite plating. 

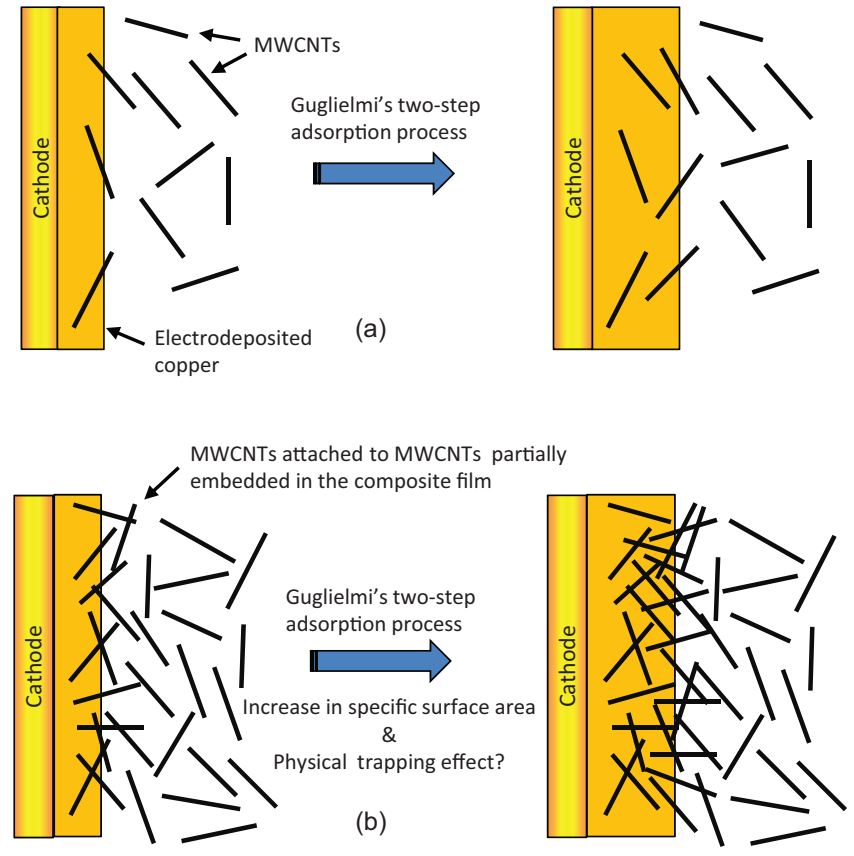

Figure 10. Schematic illustration of codeposition of MWCNTs with copper from a sulfate plating bath for (a) lower and (b) higher MWCNT concentrations.

The cathode overpotential $\eta$ also varies with PA5000 concentration as shown in Fig. 3. Therefore, if the same current density was employed for the codeposition experiments with different carbon particle concentrations, the corresponding $\eta$ may be different. In the present study, the difference in the PA5000 concentration of each plating bath might not be so significant, resulting in agreement with the Guglielmi model for lower particle concentrations. However, these topics are outside the scope of the present study, and will be the subjects of future work.

For both MWCNTs and CB, a deviation from linearity is seen in Fig. 8 at higher particle concentrations. In the case of $\mathrm{CB}$, this is likely to be due to a significant increase in the specific surface area resulting from the large roughening of the surface (Fig. $6 c, 6 d, 6 g, 6 \mathrm{~h}$ ). However, no such surface roughening is observed for the codeposition of MWCNTs (Fig. 5a-6d), although the MWCNT content does increase with increasing MWCNT concentration in the plating bath. However, since MWCNTs are fibrous in shape, their partial embedding in the surface of the composite film would also lead to an increase in the specific surface area. In Fig. 5e-5h, many such partially embedded MWCNTs can be seen in the copper matrix. This increase in the specific surface area may be one of the reasons for the deviation from the linear relationship.

As mentioned above, unlike other types of composite plating particles, the fibrous shape of MWCNTs allows them to become partially embedded in the surface of composite films, where they may physically trap MWCNTs suspended in the plating bath. The mechanism is shown schematically in Fig. 10. This additional effect could increase the amount of the MWCNTs codeposited with copper in the case of higher MWCNT concentrations. The MWCNT content in the deposits was higher than that for $\mathrm{CB}$, especially at lower particle concentrations (Fig. 8), and this may also be due to the fibrous shape of the MWCNTs.

\section{Conclusions}

The mechanism involved in the codeposition of MWCNTs with copper from a sulfate plating bath was investigated. For comparison, codeposition was also carried out using CB and copper. The effect of PA5000 on the dispersibility of the particles in the plating bath and on the electrodeposition behavior of copper was also evaluated. The PA5000 was found not only to act as a good dispersant for MWCNTs, but also to inhibit copper electrodeposition. The results suggest that when the particle concentration in the plating bath is low, codeposition might follow a Guglielmi two-step adsorption process. However, this is not the case for higher particle concentrations. It is suggested that this unique phenomenon may be due to the fibrous shape of the MWCNTs.

\section{Acknowledgment}

This work was supported by a grant-in-Aid (Kakenhi No. 22560715) from the Japan Society for the Promotion of Science (JSPS).

\section{References}

1. A. Oberlin, M. Endo, and T. Koyama, J. Cryst. Growth, 32, 335 (1976)

2. S. Iijima, Nature, 354, 56 (1991).

3. X. H. Chen, J. C. Peng, X. Q. Li, F. M. Deng, J. X. Wang, and W. Z. Li, J. Mater. Sci. Lett., 20, 2057 (2001).

4. X. H. Chen, C. S. Chen, H. N. Xiao, X. B Liu, L. P. Zhou, S. L. Li, and G. Zhang, Tribol. Int., 39, 22 (2006).

5. L. Shi, C. F. Sun, P. Gao, F. Zhou, and W. M. Liu, Surf. Coat. Technol., 200, 4870 (2006).

6. X. H. Chen, C. S. Chen, H. N. Xiao, F. Q. Cheng, G. Zhang, and G. J. Yi, Surf. Coat. Technol., 191, 351 (2005).

7. S. Arai and M. Endo, Electrochem. Solid-State Lett., 7, C25 (2004)

8. S. Arai, M. Endo, T. Sato, and A. Koide, Electrochem. Solid-State Lett., 9, C131 (2006).

9. S. Arai, T. Saito, and M. Endo, J. Electrochem. Soc., 154, D530 (2007)

10. S. Arai, T. Saito, and M. Endo, J. Electrochem. Soc., 157, D127 (2010).

11. S. Arai, T. Saito, and M. Endo, J. Electrochem. Soc., 157, D147 (2010).

12. F. K. Sauter, J. Electrochem. Soc., 110, 557 (1963).

13. D. W. Snaith and P. D. Groves, Trans. Inst. Met. Finish., 50, 95 (1972)

14. N. Guglielmi, J. Electrochem. Soc., 119, 1009 (1972).

15. J. P. Celis and J. R. Roos, Trans. Inst. Met. Finish., 52, 28 (1974).

16. J. Forester, Trans. Inst. Met. Finish., 51, 37 (1973).

17. H. Hayashi, S. Izumi, and I. Tari, J. Electrochem. Soc., 140, 362 (1993).

18. J. P. Celis, J. R. Roos, and C. Buelens, J. Electrochem. Soc., 134, 1402 (1987).

19. J. Fransaer, J. P. Celis, and J. R. Roos, J. Electrochem. Soc., 139, 413 (1992).

20. M. Endo, CHEMTECH., American Chemical Society, Sept., 568 (1998).

21. K. C. Park, M. Fujishige, K. Takeuchi, S. Arai, S. Morimoto, and M. Endo, J. Phys. Chem. Solids, 69, 2481 (2008).

22. E. Mattsson and J. O'M. Bockris, Trans. Faraday Soc., 55, 1586 (1959).

23. J. O'M. Bockris and M. Enyo, Trans. Faraday Soc., 58, 1187 (1962).

24. O. R. Brown and H. R. Thirsk, Electrochim. Acta, 10, 383 (1965).

25. I. R. Burrows, J. A. Harrison, and J. Thompson, J. Electroanal. Chem., 58, 241 (1975).

26. Z. D. Stankovic and M. Vukovic, Electrochim. Acta, 41, 2529 (1996)

27. J. O'M. Bockris and A. R. Despic, in Physical Chemistry, An Advanced Treatise Volume IXB /Electrochemistry, H. Eyring, Editor, p. 633, Academic Press, New York/London (1970). 